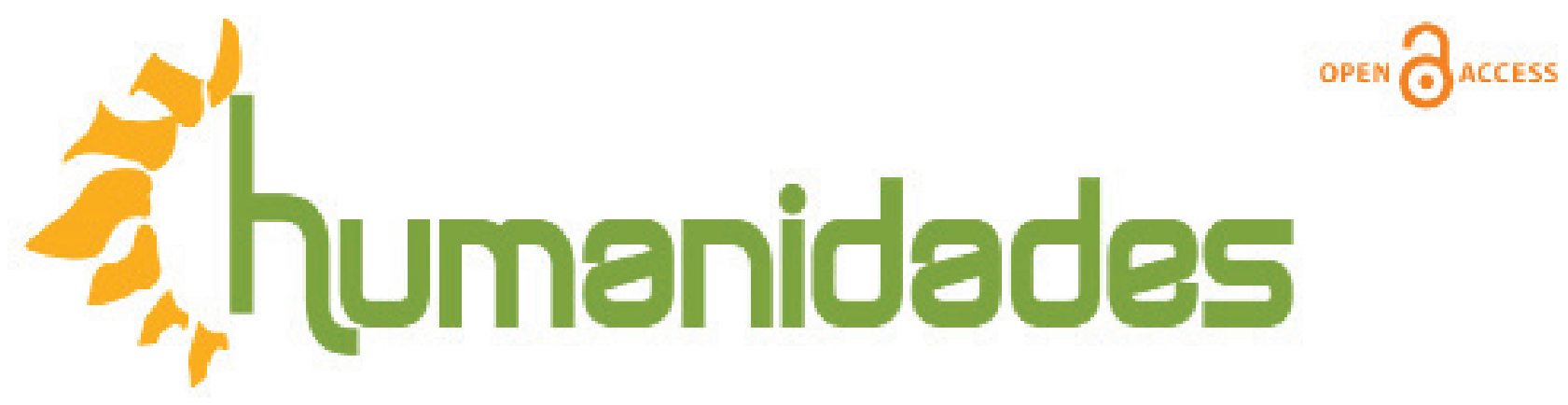

Revista de la Escuela de Estudios Generales, Universidad de Costa Rica

Enero-julio, 2019 •Volumen 9, número 1 • EISSN 2215-3934• pp. 1-5

\title{
Un mundo polarizado
}

DOI: https://doi.org/10.15517/h.v9i1.35337

\section{Arnoldo Mora Rodríguez}

Doctor en Filosofía. Exministro de cultura de la República de Costa Rica. Profesor emérito, Escuela de Estudios Generales, Universidad de Costa Rica, Costa Rica.

Correo electrónico: mora_arnoldo@hotmail.com

Todos los derechos reservados. Universidad de Costa Rica. Esta revista se encuentra licenciada con Creative Commons. Reconocimiento-NoComercial-SinObraDerivada 3.0 Costa Rica. Correo electrónico: humanidades@ucr.ac.cr/ Sitio web: http: //revistas.ucr.ac.cr/index.php/ humanidades 


\section{Un mundo polarizado}

Como consecuencia de la Guerra Fría que siguió a la peor masacre de la historia de la humanidad como fue la II Guerra Mundial, el mundo se dividió en dos bandos o polos antagónicos, no sólo ideológicamente sino en todos los ámbitos; era continuar la guerra por otros medios, especialmente recurriendo al uso de la tecnología más avanzada de que se servían los medios de comunicación masiva, las ciencias humanas, especialmente la psicología entendida como "ingeniería de la conducta" (Skinner) y la sociología (Parsons, Merton), fueron concebidas como instrumentos ideológicos para controlar las reacciones de los sectores populares. Todo ese impresionante desarrollo de las ciencias se lo apropió una minoría plutocrática que actualmente conforma el club más exclusivo - y excluyente - de la historia. Al desaparecer con el fin de siglo uno de esos polos, la Unión Soviética, debido a que no fue capaz de seguir el crecimiento exponencial de la revolución científicotécnica de sus rivales de Occidente, el mundo en la última década del siglo pasado dio la impresión de volver a lo que había sido la hegemonía de Occidente desde la llegada de Colón al Nuevo Mundo y que se había roto por la bipolaridad que caracterizó la recién pasada Guerra Fría, como era la de consolidar un imperio único que no tuviera fronteras ni geográficas, ni culturales, ni políticas, con el fin de explotar los recursos naturales y la mano de obra esclava de una periferia que vivía mayoritariamente en el Sur.

Pero la dinámica de los procesos históricos no es mecánica sino dialéctica, es decir, siempre engendra un polo contrario, de donde se nutre la energía con la que se producen los acontecimientos que configuran la historia. Esa dinámica no es más que violencia; por lo que las páginas de la historia nos hablan las más de las veces de muerte y exclusión, por un lado y, como legítima y heroica respuesta, de rebeldía y protesta por el otro. Pero ese retorno a un mundo unipolar no duró más que una corta década; a la euforia contenida en la apresurada proclama lanzada eufóricamente al mundo por los líderes occidentales anunciando mesiánicamente el triunfo del capitalismo y de sus pretendidos valores "democráticos", siguió 
muy pronto la reacción cuestionadora de una periferia abrumadoramente mayoritaria, mientras el horizonte se cubría de oscuros nubarrones anunciando apocalípticamente el inminente fin de la especie sapiens, debido a su propio e incontrolado crecimiento capaz de inducir a un suicidio colectivo por causa de un holocausto nuclear, o de la destrucción en el ámbito ecológico. La euforia se convirtió en zozobra. El entorno político que envuelve al siglo XXI no puede entenderse si no es tomando conciencia de que éste podría ser el último período de la corta trayectoria de la especie sapiens en la bioesfera. Pero la raíz del problema no radica en el método científico y su aplicación en el ámbito de la tecnología; todo lo contrario, ese es uno de los mayores - si no el mayor- logro del homo sapiens en sus aproximadamente sesenta mil años de existencia sobre la tierra. El problema está en el uso del poder que de ahí se desprende. En otras palabras, el problema de hoy para la humanidad es ético debido a que no se logra crecer en la conciencia de los valores a la velocidad que lo hacen los avances de las ciencias y su aplicación en el campo de la tecnología.

Tomando como trasfondo ese apocalíptico escenario, el segundo decenio de este siglo es testigo de la decadencia y el paulatino descenso de la hegemonía política - no así cultural - de Occidente. Las causas están a la vista según los datos estadísticos; vivimos hoy la más escandalosa desigualdad que conoce la historia de la humanidad, como lo muestra el hecho de que ocho individuos (no hablo de empresas trasnacionales ni de clanes familiares plutocráticos, sino de individuos con nombres y apellidos) poseen más riquezas y, con ello, poder político e ideológico-mediático, que el 30\% de los países que componen la humanidad actual y que llenan la franja más pobre. Occidente no ha sido capaz de resolver los problemas que él mismo ha provocado. La crisis económica de 2008 de raíces estructurales, fue temporalmente aliviada en sus peores consecuencias por el auge comercial de China; pero hoy ha vuelto a recrudecer debido a las políticas reaccionarias del actual gobierno norteamericano que cree ilusoriamente resolverla encerrándose en el ultranacionalismo, que, por desgracia, hoy parece contagiar a los tories británicos, a algunos países del Centro de Europa y al Brasil de los militares fascistoides. 
El mundo unipolar se ha convertido en un mundo polarizado; la guerra y la violencia desenfrenada en la sociedad civil, son vistas por los centros hegemónicos como instrumentos para activar la desfalleciente economía; en el entorno de Trump se menosprecian los más elementales principios del derecho internacional, incluso se llega a minimizar el rol de las Naciones Unidas; los medios de comunicación mínimamente críticos se ven cuestionados, y se legitima lo que es llamado "la postverdad", que no es más que aplicar lo que decía Hitler de que la gente considera mentiras tan sólo a las pequeñas mentiras, pero acepta sin pestañar las mentiras tanto más fácilmente cuanto más grandes sean, se violenta la división de poderes estipulada por la Constitución, se emplea un lenguaje procaz y falaz, aupando a los sectores más retardatarios de una sociedad civil cada vez más dividida y enfrentada. En Estados Unidos la frontera Sur y en Europa las costas del Mediterráneo se han convertido en trincheras de guerra rodeadas de campos de concentración, incapaces de detener y contener a legiones de gentes compuestas por humildes trabajadores con sus mujeres y sus niños, hambrientos, tanto de comida como de justicia y reconocimiento; y todo como consecuencia de siglos de injusticia social, corrupción y represión política a que los rubios del Norte han sometido a las periferias de unos pueblos, a los que sólo les interesa para obtener acumulación de plusvalía, gracias a la implacable extracción de materias primas y a la explotación de mano de obra semiesclava.

Pero ese desgarrador éxodo no se detendrá ni siquiera con amenazas de exterminio policíaco o de hambruna. Se les ve como una amenaza cuando en realidad sólo sueñan con disfrutar aunque sea una migaja de lo que se les ha pintado por los medios de comunicación hegemónicos como un paraíso. Ninguno de esos interminables grupos que atraviesan el Mediterráneo, a las desgarradoras caravanas que asedian la frontera Sur de los Estados unidos, consideran a esos países como enemigos; todo lo contrario, sienten por ellos una admiración que conmueve por su ingenuidad y autenticidad; tan sólo buscan desesperadamente satisfacer su hambre y sentir un mínimo de respeto a sus vidas tan amenazadas en sus propios países de origen. 
Muy similar a lo que, según la historia, sucedió en el último siglo antes de la caída del Imperio Romano; los pueblos del Norte no querían destruir Roma, sino tan sólo participar de sus logros civilizatorios; por eso cuando lograron el poder, acabaron con su hegemonía política, pero adoptaron la lengua y no pocas de sus instituciones; el derecho, la filosofía y el arte grecorromanos fueron reconocidos como patrimonio de la humanidad. Con ello, se dio origen a una nueva época de la historia: la cristiandad medieval.

El siglo XXI podría ser también el parto de una nueva era para la humanidad. La polarización creciente en el escenario de la política internacional amenaza con precipitar a la especie en el abismo sin fondo de su autoaniquilación, pero también podría ser el arrebol de un nuevo amanecer. De todos y cada uno de nosotros depende construir, no sólo nuestro futuro y de nuestros hijos y nietos, sino de la humanidad entera. El primer paso para lograrlo consiste en tomar conciencia de nuestra responsabilidad ciudadana. 